\title{
On Function and Roles of College Foundation in the development of Schools
}

\author{
Yujun You \\ Yangzhou University, Yangzhou, 225009, China
}

Keywords: High school. Foundation. Function

\begin{abstract}
The rise of University Education Foundation has become an important force in promoting the comprehensive promotion of Chinese,study the function and role of Chinese Education Foundation has a very important theoretical and practical significance. I think the University Foundation in the process of the development of the school include to raise funds and management, integration of resources, improve the scientific management level, grant project development boosters, supported by the hardware facilities and the development of science and technology projects, promoting the construction of spiritual civilization in universities and other functions.
\end{abstract}

\section{Introduction}

The Foundation takes advantage of the property which donated by natural persons, legal persons or other organizations for the purpose of promoting and facilitating the development of higher education and established by law as a Non-profit organizations.It originated in the Anglo American countries. In sixteenth Century,The United Kingdom has established the organization which Similar to the foundation, The development of university education foundation to peak in the latter half of the nineteenth Century USA.In the latter half of the nineteenth Century America put the development of university education foundation to the peak.With the rapid development of China's economy and society, The higher education in China has shown vigorous vitality. There is no doubt that with the rise of University Education Foundation it has been a Strength of China which to promote the comprehensive improvement of colleges and universities[1].According to incomplete statistics,the university foundation in our country has more than 200,They support the university to carry out the education activities, for example, carrying out academic conference of the forum, set up a scholarship, repair the building, support the Scientific creation.And it plays an important role in personnel training, the spiritual construction and sports activities.Compared with the mature development of abroad Education Foundation.China's university education foundation started late, and lack of experience,we can't reference the experience of abroad blindly ,In view of this background,study the function and role of China's higher education foundation has a very important theory and practice sense.

\section{Raise and manage funds, increase the income}

University education foundation is a kind of operation mode of University and market integration,the existing of foundation has rich the source of funding for education and the college has formed a diversified income, the proportion of government funding decreased,the college raised.Since 1990 , in American the proportion of government funding has a declining trend , at the same time the proportion of individual donations and contract forms of donation was increased.The higher education investment also showed a rising trend.America law shave always encouraged the implementation of social donation to universities,such as Harvard University. In 2009 the donated assets they received reached $\$ 26000000000$,the proportion of the school's annual budget accounted for nearly $1 / 3$.It has become one of the major sources of income of Harvard university.

At present the main income of higher education institutions in our country still come from state financial allocations,But with the development of education,more and more funds needed,Colleges and universities must improve the ability of self raised funds.The development of university 
education foundation is favorable measures to expand the college fund-raising [2].At present,whether in economic or educational fields have a fierce competition,the Investment of educational appropriations has become the key factors to Restricting the development of universities and the competition strength.The scale of higher education in China has a stride development,From 3400000 in 1998 to 20000000 of 2010,From the elite education to popular education ,This is a dramatic change,maybe it was unbelievable for the rest of the world.In the process of realizing the grand goal ,In the process of elite education to mass education mode,Domestic education field colleagues paid a great deal of effort and sweat, the increase of fixed assets in universities has promote the infrastructure of colleges and universities,Improve the Equipment of The teachers aspect.According to the survey report,at present The construction fund in our country is only 1/4 of what is needed.This is far to meeting the construction of institutions of higher learning, Therefore,varied channel of financing has become a necessary consideration of steady development in Colleges and Universities.It is no doubt that The construction of University Foundation has provide a superb solution for this problem.In the basic construction of colleges and universities in China include the five hundred billion,national fiscal spending just fifty billion,more than 2000 billion was resolution by debt ,But there are more than 2000 billion to all aspects of social support to survive.The foundation plays a vital role in this process.

The fund also can use the scientific mode of investment to ensure the Fund of funds to keep value.Enhance the vigor and vitality of the foundation by diversified operation.Domestic university such as Tsinghua University, Zhejiang University,Shanghai Jiaotong University are commissioned professional Russian investment company and national securities investment funds to carry on the effective management,and Cooperation with relevant departments to obtaining benefit.

\section{The integration of resources, promote the construction of colleges and Universities}

Actually, The foundation also plays an important role in integrating resources.It will promote the ability of attracting the manpower and material resources and money and other valuable resources to support the progress of the University.It proved the old saying that the development depends on the strength, and the strength depend on construction, any form of construction is depend on capital chain which is the Source of Hardware based.In the past,it is difficult to achieve the strategic as the most of the goal colleges and universities adopt the method purely to to increase production and mutual restraint the balance, With the strategic target as the center,Integrated absorption of various internal and external sources of funds and strength is a necessary condition to achieve the rapid development of the [3].University education foundation is a good mechanism system and resources, The utility model has the advantages of both inside and outside can bring all aspects of manpower and money, in the form of donations and contributions. And with the integration of science and integration,Gradually formed a mechanism which directed by the strategy, the platform as the carrier, It can distribute and coordinate according to the demand of decision on all aspects of the university, put the incremental resources into the Key development areas or to be developed areas.But if the incremental resources limited,we can consider redistributing the resource.

In the current our country university research funding sources,the investment of Enterprises and private and government has accounted for more than a half.Enterprises or other units and colleges start cooperation in scientific research with colleges and Universities Is the main delegate form complete technical goals or the corresponding research results, more attention is paid to the immediate interests and practical effect.The fund is open and free,It is not limited to the use of funds,also can not be control by donors' desires, Therefore the university foundation to achieve continuously in some potential or key project investment,In order to improve the basic conditions of domestic colleges and universities, and beneficial to realize the balanced development of various fields. 


\section{To raise the level of scientific management}

System construction is the key step to achieve the strategic decision to implement,and also an important way to enhance the level of development of colleges and universities, The reform and improvement of defects hinder the development of a policy framework and institutional innovation is of significance.At present,the internal affairs of college has become more complex,It is necessary for universities to have a scientific revolution to the inside of organization .To build a solid administrative service of a high level of colleges and universities, To ensure the smooth operation of colleges and universities.The foundation is a non-profit organization and it is relatively flexible and free, The characteristic reaction in the mode of operation of the internal governance mechanism, and incentive mode and supervision and evaluation system on [4],The development and system construction of university foundation can provide good experience and Enlightenment for the development of colleges and universities and innovation,And to promote the organization in accordance with the law and social norms in the development of school policy, based on the value of efficiency and effectiveness, achieve the public welfare and fairness goals.

China's university education foundation is the fund-raising organization embedded in the internal, which has a dual nature, and it has certain administrative properties, but no actual administrative power. It is not a simple social groups, but it is a social group. However, it is the duality which determines the fund will maintain a close relationship with the university timely. Launches of the university fund's work is not separate from the university leadership decision-making of every department, and the foundation of public welfare with the object and purpose builds strong bridges for the communication of school and the society and market.This bridge helps the university achieve its duty and mission, and promote the development of scientific system and the significance of human construction activities. In the process of university's development, University Foundation helps the realization of public interests, carrying the arduous task and play an important function, provides a strong support for the development of our higher education and the modernization of the country.

\section{The foundation is the booster of grant of project development}

First, donating funds to the Foundation, enterprises will enjoy the preferential taxation, which greatly aroused the enthusiasm of enterprises foundation established scholarships in universities. University Education Foundation has a single day in the thick of the fund-raising advantage, such as enterprises enjoy preferential tax treatment.Investigation shows that, although the tax incentives not to decide whether an enterprise to make donations, the amount of tax will influence them to make the amount of donations. In 2007, Ministry of Finance and the State Administration of Taxation issued a notice"about the public welfare relief donations to inform policy and management of pre tax deduction"."Notice" provisions: Approved by the civil affairs department of nonprofit public welfare social groups and foundation, who meet the relevant requirements, and confirmed by the finance and tax departments, through the taxpayer for public welfare relief donations, according to the provisions of tax laws and regulations and related policies, to pay the corporate and personal income tax is calculated at the pre income tax deduction. This means that, the foundation can fully enjoy the preferential tax policy donation[5]. In addition, the provisions of the new "enterprise income tax law": enterprise's expenditures for public welfare donations, within $12 \%$ of the total annual profits, it is permitted to be deducted from taxable income.

Second, the fund will make the scholarship management trend of standardization and rationalization, and promote the scholarship incentive, aid effectiveness. The overall management of the foundation award grants, greater play award grants function. Before the establishment of the foundation ,scholarships are generally managed by the administrative department of the college ,and it is easy to cause scholarships of statistics and management oversight.The lack of scholarship management is not conducive to post liaison and communication with the donor. The establishment of the foundation, will mean by representatives of the school management and coordination including grants, donations to schools of all kinds, and the foundation also can consider to set standards, 
scholarships and other awards for execution. Foundation award grants management take four principles of unity, the unified account, receipt, certificate, unified audit. 1. unified account: All money award grants are imported school education fund accounts; 2. unified receipt: Foundation unified receipt to the unit or individual donations grants; 3.unified certificate: Foundation issued uniform certificate of donation to the unit or individual donor grants; 4. unified audit: In the fund account audit all grants entry[6].

Third, the establishment of the foundation can improve the efficiency of raising award grants, and have reasonable conformity to the school resources. Before the establishment of the foundation, college scholarships are limited, the formation of a grant of the small amount of the situation, on the other hand also led to the gap between income distribution, such as the high school of business, School of business and economics alumni economic strength, and have more exposure opportunities and enterprise, the establishment of a number of grants, scholarships, but the philosophy of biological unpopular departments is restricted.After the foundation was established, it as a fundraiser for the specialized agencies, permits the system within the scope of the initiative through multiple channels to raise scholarship, further expands the source awards grants. Through the investigation of specific school to its own situation and strategic planning, and a thorough research in the related departments, departments, funds will be able to design some specific, different levels, different direction and the names of the grant project. The foundation also can take the initiative to the mining potential donor or mechanism, specific requirements can also be combined with the donor and setting the corresponding grants program, and the implementation of the project as the center to do a series of preparing and supporting services before and after[7].In addition, the school foundation also partnered with departments, and multi-level planning system is gradually formed. In the full use of fund's financial management and fund-raising advantage, Take the form of varied and flexible management services to assist faculty grants to operate, given reasonable guidance and assistance in the faculties and donor communication process, in order to obtain the maximum possible overall interests.

\section{Subsidize construction of facilities and research and development project}

Hardware infrastructure construction projects include the construction of campus infrastructure, and teaching scientific research project. Teaching research project refers to the donor or donation units to improve teaching hardware condition of colleges and universities as the premise, to the fund for teaching scientific research equipment. The campus infrastructure includes university buildings or landscape architecture and other infrastructure, in addition to the huge buildings, infrastructure also includes a small amount, such as the dining room, hall and room etc..

The development of scientific research project is to promote the development of teaching and scientific research function, such as the development project cooperation between colleges and enterprises, and scientific research fund project. Objects supported by the scientific research development fund project includes research fund of teachers' scientific research funds and students. Scientific research fund for support of Teachers College Teachers' research and innovative research work; the main purpose is to promote students' scientific research funds to do more practice and creative activities in the field of scientific research, the focus is to train the ability of scientific research.Examples of prominent such as the establishment of American Tang Zhongying foundation, the foundation is funded by Chinese American Mr.Tang Zhongying.Since 2003, the Tang Zhongying foundation has donated Nanjing University 50000000 yuan to found the Nanjing micro structure of national laboratory. The Tang Zhongying Foundation's move is the first name of a country, government, universities and the foundation of State Key Laboratory of this co founded, and it has a creative significance in the history of the development of China's foundation, and it greatly stimulated the enthusiasm of teachers and students in Nanjing University for the scientific research work, and promote the development of the scientific research of Nanjing University [8].

The fund will be able to promote the construction of spiritual civilization of colleges and Universities 
The public welfare foundation bearing the public service mission, publicity and public idea and behavior is an important work content, the prospects, motto and mission of pursuing into fund initiative, to build and the correct value orientation implementation of campus spiritual culture. To raise funds through the creation of infrastructure or scholarship stipend system general form, can also open to cooperation with domestic and foreign institutions to carry out personnel training projects; and marketing or promotion besides fund-raising project itself, more meaningful is a kind of propaganda and the image of university culture, culture building foundation [9].

Promote the forming of citizen responsibility consciousness, and enrich citizens join public channel. In American , the donation has become one of the excellent tradition of the society. In China, donation awareness of people in our society is still relatively weak. Donation atmosphere is not strong. Therefore the University Foundation based on the University and the society of the efforts of all parties, has indelible significance for promoting the donation and the cultivation of citizen consciousness of social responsibility.

It helps to promote the good social atmosphere and the moral construction of citizens, the formation of noble morality. University Foundation in the unity of social idle resources and providing funds for colleges and universities, greatly stimulated their dedication, enthusiasm, arouse the enthusiasm of the public to donate education and support education influence character by environment, stimulate social citizen moral quality of altruistic cooperation, thus greatly promoting the construction pace of Chinese spiritual civilization [10].

In short, as one of the link between university and society, university education foundation brings a new way of new ways to ease the financial pressure, to the university, but also can contribute to risk management and risk aversion effect.

\section{Acknowledgments}

The source of the fund: Ministry of education of humanities and social science research project in general ,the fund project's name is "college fund governance structure and mechanism research" , Project grant NO: 11YJC8880147.

\section{References}

[1] Guo Xiujing. The present situation analysis and development path selection of our university education foundation. Journal of Tianjin University ,Social Sciences Edition, 2009, 32:34-35

[2] Chen Yeqin. Study of benign operation of nonprofit funds. Central South University, 2012

[3] Fan Minglin. The interaction between NGOs and the government. Sociological Research .2010, 387-403

[4] Gao Jianguo. The external supervision mechanism of America charitable donation giving enlightenment to China. Exploration and Contention, 2010, 7:26

[5] Gao Zhihong. On the charity benefit and its remodeling. Seeking Truth, 2012, 395

[6] Li Changchun. The supervision of China charity. Journal of Jinan University ,Philosophy Social Science Edition, 2013, 6

[7] Zhang Zuping. Research on China's charity fund-raising. Community management research, 2011, 1:12

[8] He Yongping. The board of directors of the public university governance system construction research. Southwest University, 2012

[9] Wang Zhaobin. USA charitable foundation evolution and its social function. The world economic and political BBS, 2011, 4010 